\title{
Efficiency of Indian Option Market: Estimation of Future Market Volatility Using Implied Volatility\#
}

\author{
T. Viswanathan ${ }^{1 *}$, R. Sriram ${ }^{2}$ and Prarthana Mukherjee ${ }^{3}$ \\ ${ }^{1}$ Assistant Professor, ${ }^{2,3}$ Student Research Associate, Symbiosis Institute of Business Management Bengaluru \\ (SIBM), Electronic City - 560100, Bengaluru, Karnataka, India
}

\section{Abstract}

Forecasting volatility is a key process in pricing stock and index options. Accurate forecasting of future volatility would facilitate the traders and investors to make an informed decision. The study examines the market efficiency of exchange traded index options in India. We investigate the predictive power of implied volatility of Nifty index options in forecasting the future stock market volatility. The efficient market hypothesis believes that the implied contains all past information, thereby making it a superior volatility forecast for the underlying asset. Our study is based on the implied volatility of Nifty index options for the years between 2010 and 2018. In this paper, we compare the accuracy of expected future volatility using implied volatility concerning historical volatility. We study the implied volatility for Nifty 50 index option over the last seven years and compare the results against the ARMA model and historical forecasts to re-establish the superiority of implied volatility and efficiency of the Indian option market.

Keywords: Historical Volatility, Implied Volatility, Volatility Forecast

\section{Introduction}

Forecasting volatility is an inherent process in portfolio management. In general, the volatility of stock and market returns are measured based on the standard deviation of the historical price. The future volatility is estimated based on historical volatility. Such estimates may not provide accurate future volatility, because the price movement in the past does not repeat the same pattern in the future. Researchers have estimated various measures of volatility such as intraday volatility, realised variance and implied volatility. Among other measures, implied volatility forms a significant part in forecasting volatility.
Implied volatility is one of the major factors to be considered while trading in options. The changes in implied volatility provide a signal to understand the gyrations in options contract. It indicates the possibility of price fluctuation in the price of the underlying asset. It helps investors gauge future market volatility. Implied volatility is one of the six parameters used in the option pricing model. The options trader can increase the probability of earning a profit by appropriately taking a long or short position based on the implied volatility. The option with short time to maturity is more volatile than the options with long term maturity. 
Historical volatility is an ex post volatility due to its calculation based on past prices. Implied volatility serves as an estimate of future volatility of a stock price/ market return. It is perceived as the volatility implied by the market on an asset. It is mostly used in option pricing. Theoretically, there is a relationship between implied volatility and market movement, Andrew Szakmarya et. al (2003) The bearish market tends to increase implied volatility and vice versa. Increase in implied volatility increases the risk. It is due to the investor's perception that the market will be bearish when there is an increase in volatility. Therefore, the relationship between implied volatility and historical volatility needs to be modelled for forecasting volatility.

\section{Literature Review}

Karam Pal Narwal and Purva Chhabra, (2018) study provides an insight of implied volatility vis a vis informational efficiency. The purpose of this paper was to provide a comprehensive synthesis of past studies regarding the informational content of indices that measure volatility and reviews the empirical and theoretical research studies of the last five decades. It was reaffirmed that overall volatility indices outperform predictions based on the historical volatility measures to predict future realised volatility.

Henry Huang, Kent Wang and Zhanglong Wang (March 2016) applied the Martingale properties of the Model Free Forward Variance (MFFV) to examine the efficiency of S\&P 500 options market. By examining samples before and after the 2008 financial crisis, the options market is found to be inefficient and is mainly due to the subprime crisis. The study found that the lagged variance can be used to forecast future variance.

Emmanuel Anoruo and Vasudeva NR Murthy (November 2016) examined the relationship between REIT returns and implied volatility. They used a frequency domain approach to allow shocks to vary across frequency bands. The study concludes that the knowledge of implied volatility facilitates the investors to predict movement in the capital market.

Abhijeet Chandra and Thenmozhi (March, 2015). Their study examines the asymmetric relationship between the India volatility index (India VIX) and stock market returns. It is found that India VIX captures stock market volatility better than traditional measures of volatility including ARCH/GARCH class of models.

Imlak Shaikh and Puja Padhi (2014a) examined the interaction of "volatility smile", term structure and implied volatility of S\&P 500 and Nifty index option. The study found that implied volatility violates the underlying assuming of the Black Scholes option pricing model. There is evidence of the existence of $U$ shaped volatility smile for Indian options market.

Christensen B.J and Prabhala NR (1998), Imlak Shaikh and Puja Padhi (2016) investigated the contemporaneous inter-temporal relationship between implied volatility index and stock returns. The study found that negative returns induce more volatility as compared to positive returns. It is concluded that long run inter-temporal contemporaneous relation persists between the implied volatility and stock market returns.

Percheklii (2014) study compared the predictive power or historical and implied volatility. It is found that implied volatility is inefficient to predict volatility and it provides a biased estimate of the Russian stock market volatility. The historical volatility outperforms implied volatility for data sets that reflect three market series.

Kumar (2012) examined the volatility transmission between India and developed countries stock market. The results indicate the volatility of India stock market (VIX) is negatively correlated to other stock markets. The study further concludes the predict power of VIX to forecast future volatility.

Costas Siriopoulos and Athanasios Fassas (2009) analysed the information content concerning realised volatility and implied volatility. The findings of the study show that the implied volatility indices include information about future volatility as compared to similar study was done by Karan Pal and Purva Chhabra (2017) on the asymmetric relationship between volatility index and assets. The study found the presence of the asymmetric relationship between implied volatility and equity index returns. 


\section{Objectives of the Study}

1. To examine whether the implied volatility provides a price discovery mechanism to forecast market returns,

2. To predict the future volatility using the market estimate of implied volatility and evaluate the accuracy of various forecasting models,

3. To examine whether the futures market provides a price discovery mechanism, and

4. To examine the causal relationship between market return and volatility index.

\section{Hypotheses of the Study}

For the enhancement of the study, the following hypotheses have been framed.

- $\mathrm{H}_{0}-$ There is unit root in the series of market return and volatility index,

- $\mathrm{H}_{0}-$ There is no volatility transmission for the future to spot market,

- $\mathrm{H}_{0}$-The market return does not Granger cause implied volatility, and

- $\mathrm{H}_{0}$ - The volatility index not Granger Cause market return.

\section{Research Methodology}

\subsection{Date Collection}

The study uses the secondary data of historical Nifty index and India volatility index (VIX). The study covers the period between 2010 and 2018. Daily and monthly returns are calculated from the historical data. The frequency of return is selected according to the fitness of data in the forecasting models.

\subsection{Tools Employed}

Application of Econometric tools requires the data to be stationary. Non stationary time series data produce a biased estimate of the future and results in spurious regression. Augmented Dickey Fuller Test is used to examine whether the historical series of market returns and IV are stationary. The unit root test is applied at the level and first differences of Nifty and VIX time series data. Engle Granger Test examines whether the causal relation between markets returns and implied volatility. The relationship could be unidirectional or bidirectional.

\subsection{Augmented Dickey Fuller Test}

The historical data of Nifty and VIX is taken for unit root test. The following is the equation of the ADF test.

$$
\Delta y_{t}=\alpha+\beta_{1} t+\beta_{2} t^{2}+\gamma y_{t-1}+\phi_{1} \Delta y_{t-1}+\cdots+\phi_{p-1} \Delta y_{t-p+1}+\varepsilon_{t}
$$

Where:

- $\Delta \mathrm{y}_{\mathrm{t}}=$ change in the dependent variable,

- $\alpha$ is a coefficient,

- $\beta_{1}$ is the time trend coefficient, and

- $\beta_{2}$ is the squared time trend coefficient.

\subsection{Granger Causality Test}

The Granger Causality test examines whether one-time series shows a causal relationship with another series. If the causal relationship is statistically significant, then one variable can be used to predict another variable. The test was proposed by Granger (1969) and popularised by Sims (1972).

Steps involved in Granger Causality Test regress the first orders of NIFTY with VIX for the period of observation. Estimate the unrestricted ordinary least square equation by assuming a lag length $\mathrm{p}$.

$$
\begin{gathered}
x_{t}=c_{1}+\sum_{i=1}^{p} \alpha_{i} x_{t-i}+\sum_{i=1}^{p} \beta_{i} y_{t-i}+u_{t} \\
H_{0}: \beta_{1}=\beta_{2}=\ldots \beta_{p}=0
\end{gathered}
$$

Estimate the following OLS equation and use the F test to check for significance.

$$
x_{t}=c_{t}+\sum_{i=1}^{p} \gamma_{i} x_{t-i}+e_{t}
$$

Compare the error terms in both the equation.

$$
R S S_{1}=\sum_{t=1}^{T} \hat{u}_{t}^{2} \quad R S S_{0}=\sum_{t=1}^{T} \hat{e}_{t}^{2}
$$

If the test result is significant, then reject the null hypothesis that $Y$ does not Granger-cause $X$. 


$$
S_{1}=\frac{\left(R S S_{0}-R S S_{1}\right) / p}{R S S_{1} /(T-2 p-1)} \sim F_{p}, T-2 p-1
$$

It is noted that with lagged dependent variables, as in Granger-causality regressions, the test is valid only asymptotically. An asymptotically equivalent test is given by:

$$
S_{1}=\frac{T\left(R S S_{0}-R S S_{1}\right)}{R S S_{1}} \sim \chi^{2}(p)
$$

\section{Empirical Results}

\subsection{Descriptive Statistics}

Table 1. Summary statistics of Nifty and Volatility index

\begin{tabular}{|l|l|l|l|l|}
\hline \multirow{2}{*}{ Particulars } & \multicolumn{2}{|l|}{ Daily return } & \multicolumn{2}{l|}{ Monthly return } \\
\cline { 2 - 5 } & NIFTY & VIX & NIFTY & VIX \\
\hline Mean & 0.000355 & -0.000301 & 0.007165 & -0.005357 \\
\hline Median & 0.000500 & -0.002100 & 0.006050 & -0.003150 \\
\hline Maximum & 0.037400 & 0.496900 & 0.117200 & 0.523600 \\
\hline Minimum & -0.061000 & -0.414400 & -0.108100 & -0.627400 \\
\hline Standard deviation & 0.009790 & 0.051348 & 0.045675 & 0.187006 \\
\hline Skewness & -0.199170 & 0.485339 & -0.014129 & 0.082776 \\
\hline Kurtosis & 4.767486 & 10.86415 & 2.942849 & 3.824307 \\
\hline Jarque Bera & 290.7908 & 5561.887 & 0.016598 & 2.886462 \\
\hline Probability & 0.000000 & 0.000000 & 0.991735 & 0.236163 \\
\hline
\end{tabular}

Table 1, we can see that Nifty data is negatively skewed for both daily returns and monthly returns category. This shows that Nifty data is not normally distributed and is not symmetrical on the left side of the mean. For Nifty Daily Returns data, this skewness value is higher indicating a larger number of observations which have returned less than mean. Comparing the kurtosis values, NIFTY daily returns data has a much longer left tail (value $>3$ ) indicating a higher number of outliers.

On the other hand, for VIX data the skewness values for both the categories, with daily and monthly returns are positive. This proves that VIX data is also not normal and thus not symmetrical. From the kurtosis values we see that for daily returns, VIX daily returns has a longer right tail compared to monthly returns data.

VIX shows much higher variability than Nifty during the same period from 2010 to 2018 July (Figure 1).

Figure 2, Box Plot we can see that for Nifty it has a higher number of outliers with values less than median showing that data is skewed on the left and hence is not normal. For VIX, it has a higher number of outliers with values greater than the median establishing the fact that data is not normal and is skewed on the right. The

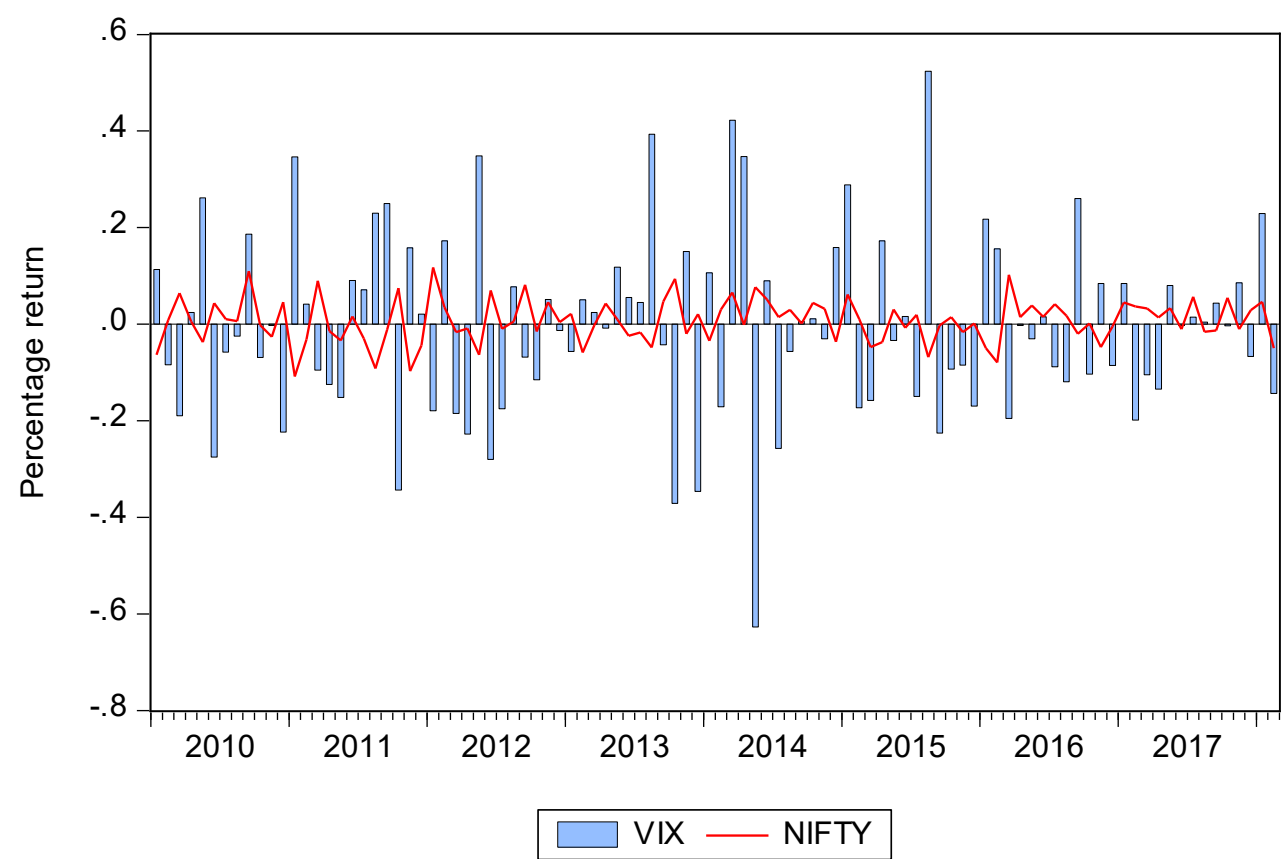

Figure 1. Monthly return of Nifty and Volatility index for the period between 2010 and 2018. 

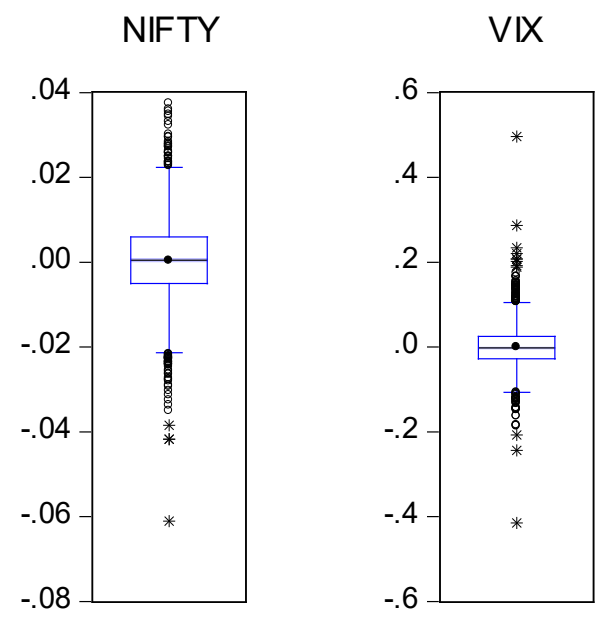

Figure 2. Box plot: Daily return of Nifty and VIX

inter-quartile range for nifty is larger than VIX. Hencea large numbers of data points from NIFTY follow the normal curve. Nifty has much higher variability in the data compared to VIX instead of its longer whiskers as seen on the graph.

\subsection{Augmented Dickey Fuller Test}

Table 2. Unit root test of Nifty returns and Volatility Index

\begin{tabular}{|l|l|l|l|}
\hline \multirow{2}{*}{ Variables } & \multicolumn{3}{|l|}{ Level } \\
\cline { 2 - 4 } & Intercept & Intercept and trend & None \\
\hline Nifty return & $(0.008658)$ & $(0.005697)$ & $\left(-10.51897^{\star}\right)$ \\
\hline VIX & $(-0.007760)$ & $(-0.014583)$ & $(-1.29976)$ \\
\hline
\end{tabular}

Values in () indicate significance level @ $5 \%$ or Rejection of Null Hypothesis, Maximum lag (Automatic) - 11, Schwarz Info Criterion, *t statistic
Application of econometric tools for forecasting requires the historical data to be stationary. Such series provides an accurate, unbiased linear estimate of future price, return and volatility. Stationary time series is a stochastic process whose parameters such as mean and variance remain constant irrespective of time. The trend analysis (Table 2 and Figure 3 ) of Nifty return shows the monthly returns exhibit positive and negative returns with a mean of $0.72 \%$ and a standard deviation of $4.6 \%$. The volatility index shows a mean of $-0.54 \%$ with a standard deviation of $18.7 \%$. The visual observation of both the series seems to be stationary since the series has to mean close to zero and approximately constant variance. We apply Augmented Dickey Fuller test to check for a unit root in the series of NIFTY and VIX. The maximum lag is selected based on the Schwarz Info Criterion and the results of $t$ statistic are compared with the critical values of Dickey Fuller. The significance of the results is tested at 5\% level. We apply the unit root test at three levels, i.e. Random walk (No drift and Trend) $\ddot{A}_{y}=\gamma y_{t-1}+\varepsilon_{t}$, Drift without linear time trend $\Delta_{\mathrm{y}}=\mathrm{a}_{0}+\gamma \mathrm{y}_{\mathrm{t}-1}+\varepsilon_{\mathrm{t}}$, Drift and linear time trend. $\ddot{A}_{y_{t}}=a_{0}+\gamma y_{t-1}+a_{2} t+a_{t}$. The ADF test for Nifty return indicates the series is stationary at levels for intercept, trend and intercept and without constant. Similarly, series of VIX are also stationary at a level for all the three equations. It is inferred that NIFTY and VIX return are I(0) variables that indicate stationarity at levels.

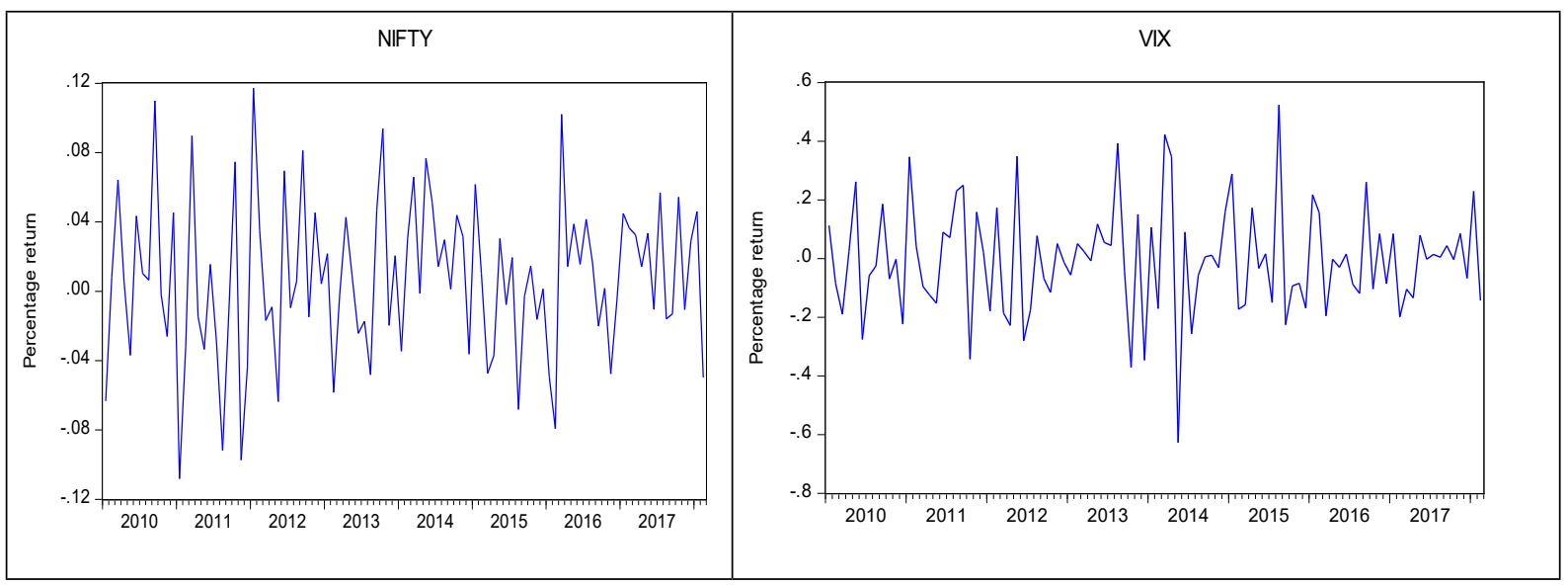

Figure 3. Monthly return of NIFTY and Volatility Index for the period between 2010 and 2018. 


\subsection{Test for Equality of Variance between NIFTY Return and VIX}

India VIX is constructed based on the price of Nifty index options. Any change in the Nifty index will affect the option prices and thus will have an impact on the volatility. Generally, VIX shows a negative relationship with Nifty return. High volatility in the market affects the investor's sentiment that leads a decrease in volume and market return. Low volatility would boot investors' confidence and bring more volume and increase the market return. We examine the nature of the association between Nifty and VIX by applying the test of equality of variances. The following are the hypothesis for the test (Table 3):

Null Hypothesis: $\mathrm{H}_{0}: \quad \sigma 21=\sigma 22=\ldots=\sigma 2 k$

Alternate hypothesis: $\mathrm{H}_{\mathrm{a}}: \quad \sigma 2 i \neq \sigma 2 j$ for at least one pair $(i, j)$.

Table 3. Test of equality of variance between NIFTY and VIX

\begin{tabular}{|l|l|l|l|}
\hline Test for Equality of Variances Between Series \\
\hline Method & df & Value & Probability \\
\hline F-test & $(97,97)$ & 16.76336 & 0.0000 \\
\hline Siegel-Tukey & & 7.509997 & 0.0000 \\
\hline Bartlett & 1 & 149.4618 & 0.0000 \\
\hline Levene & $(1,194)$ & 71.34741 & 0.0000 \\
\hline Brown-Forsythe & $(1,194)$ & 71.23686 & 0.0000 \\
\hline Category Statistics & & & \\
\hline
\end{tabular}

\begin{tabular}{|l|l|l|l|l|l|}
\hline & & & Mean Abs. & Mean Abs. & Mean Tukey \\
\hline Variable & Count & Std. Dev. & Mean Diff. & Median Diff. & Siegel Rank \\
\hline NIFTY & 98 & 0.045675 & 0.035887 & 0.035873 & 128.9337 \\
\hline VIX & 98 & 0.187006 & 0.141858 & 0.141822 & 68.06633 \\
\hline All & 196 & 0.135916 & 0.088873 & 0.088848 & 98.50000 \\
\hline
\end{tabular}

The test of equality of variance examines whether two populations have the same variance. The hypothesis is tested by parametric test (F-test) and Non parametric tests (Siegel-Tukey, Bartlett, Levene and Brown Forsythe). Equal variances between NIFTY and VIX indicates homogeneity of variance otherwise heteroscedastic. F test and Bartlett test are applied when the data follows a normal distribution. Levene's test an alternative to Bartlett test used when the series deviates from a normal distribution. Brown-Forsythe uses either the median or the trimmed mean in addition to the mean value. The test is best suited when there is kurtosis and skweness in the data. All test results are significant@5\% level. Therefore, the null hypothesis of equal variance is rejected, and it is inferred that the variance NIFTY and VIX are not constant across time. We found that there is no evidence to say the variance between NIFT and VIX is equal.

\subsection{Simple Linear Regression - Static Forecast of Nifty Returns}

Financial markets exhibit a strong relationship between market performance and volatility. Increase in stock market returns tends to decrease the volatility and vice versa. Volatility is measured using the standard deviation of historical price movement of the market index. However historical volatility does not provide an accurate forecast of future volatility. The volatility index (VIX) measures the implied volatility i.e. market estimation of future volatility. Therefore, any change in VIX would indicate future volatility. Any increase or decrease in VIX would act as a lead indicator to market return establishing a relationship between returns and volatility. We apply simple linear regression -static forecast model to forecast nifty returns.

\begin{tabular}{|l|l|l|l|l|}
\hline Table 4. Static forecast of Nifty returns \\
\hline Dependent Variable & NIFTY & & & \\
\hline Sample & $\begin{array}{l}2010 \mathrm{M} 01 \\
2016 \mathrm{M} 02\end{array}$ & & & \\
\hline Variable & Coefficient & $\begin{array}{l}\text { Standard } \\
\text { Error }\end{array}$ & t-Statistic & Prob \\
\hline C & 0.003771 & 0.004995 & 0.754923 & 0.4528 \\
\hline VIX & -0.111521 & 0.024515 & -4.549084 & 0.0000 \\
\hline R-Squared & 0.223252 & & & \\
\hline Adjusted R Squared & 0.212464 & & & \\
\hline
\end{tabular}

Table 4 and Figure 4 shows the results of the simple linear regression of nifty index and VIX. The market index is taken as the regress and VIX as the regressor. Since the equation does not include the lag value of regress and, the forecasting is said to be static. The historical time series is classified in to two parts i.e. the observation and forecasting period. The observation period is between 2010M01 and 2016M02 and the forecasting period in between 2016M03 and 2018M02. The forecasted market returns are compared with the 


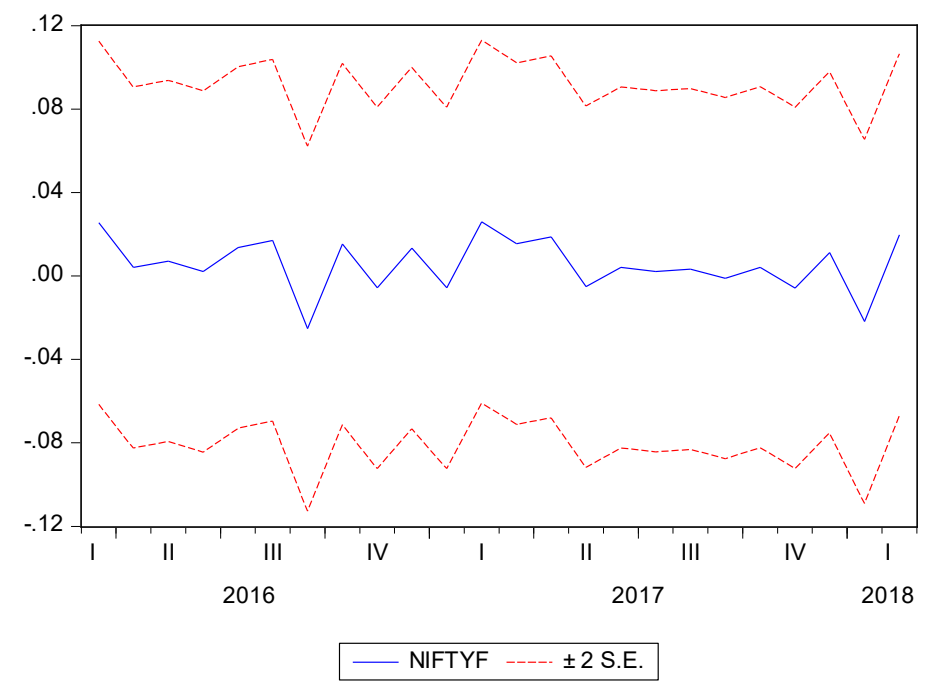

\begin{tabular}{|ll|}
\hline \multicolumn{2}{|l|}{$\begin{array}{l}\text { Forecast: NIFTYF } \\
\text { Actual: NIFTY }\end{array}$} \\
Forecast sample: 2016M03 2018M02 \\
Included observations: 24 \\
Root Mean Squared Error & 0.035764 \\
Mean Absolute Error & 0.027951 \\
Mean Abs. Percent Error & 123.2195 \\
Theil Inequality Coefficient & 0.685197 \\
$\quad$ Bias Proportion & 0.101988 \\
$\quad$ Variance Proportion & 0.359956 \\
Covariance Proportion & 0.538057 \\
\hline
\end{tabular}

Figure 4. Static forecast of Nifty returns.

actual and plotted in Figure 5 along with the residuals. The forecasting accuracy of the statistical model is tested based on the root mean squared error Theil $U$ Statistic. The linear regression results show a root mean squared error of $3.57 \%$. The accuracy of simple linear regression to forecast is interpreted by using Theil U Statistic. The model is considered to be the best fit if the $U$ stat value is less than 1 . The obtained $U$ stat value is 0.685 . Any value below one is considered to be better guessing as per the guidelines. Therefore, is it inferred that simple linear regression may provide an unbiased estimate of future return.

\subsection{Residual Diagnostics}

Table 5. Breusch-Godfrey Serial Correlation LM Test

\begin{tabular}{|l|l|l|l|l|}
\hline F-statistic & 3.581476 & \multicolumn{2}{|l|}{ Prob. F(2,70) } & 0.0330 \\
\hline Obs*R-squared & 6.869338 & \multicolumn{2}{|c|}{ Prob. Chi-Square(2) } & 0.0322 \\
\hline Variable & Coefficient & Std. Error & t-Statistic & Prob. \\
\hline C & 0.000388 & 0.004828 & 0.080378 & 0.9362 \\
\hline VIX & -0.008556 & 0.023950 & -0.357254 & 0.7220 \\
\hline RESID (-1) & -0.004674 & 0.116047 & -0.040273 & 0.9680 \\
\hline RESID (-2) & -0.313746 & 0.117231 & -2.676298 & 0.0093 \\
\hline R-squared & 0.092829 & Mean dependent var & $2.25 \mathrm{E}-18$ \\
\hline $\begin{array}{l}\text { Adjusted } \\
\text { R-squared }\end{array}$ & 0.053950 & \multicolumn{2}{|l|}{ S.D. dependent var } & 0.042671 \\
\hline S.E. of regression & 0.041504 & \multicolumn{2}{|l|}{ Akaike info criterion } & -3.473520 \\
\hline Sum squared resid & 0.120580 & \multicolumn{2}{|c|}{ Schwarz criterion } & -3.348976 \\
\hline Log likelihood & 132.5202 & \multicolumn{2}{|l|}{ Hannan-Quinn criter. } & -3.423838 \\
\hline F-statistic & 2.387651 & \multicolumn{2}{|l|}{ Durbin-Watson stat } & 1.825684 \\
\hline Prob (F-statistic) & 0.076236 & \multicolumn{4}{|l}{} \\
\hline
\end{tabular}

Application of linear regression and testing of the hypothesis requires the series to be normally distributed. The normality is tested using JarqueBera test under the null hypothesis of normal distribution vs non-normal distribution. Since the obtained probability is more than $5 \%$, the test is not statistically significant (a) 5\% level. It shows the residuals of liner regression are not normally distributed. Breush Godfrey LM Test (Table 5) is applied to examine whether the residuals are correlated with the lagged value of itself causing an auto correlation. Presence of auto correlation may produce biased coefficients and inflated $\mathrm{R}^{2}$ value. The LM test shows there is no auto correlation in the residuals. Breusch Pegan Godfrey test is used to test whether the variance of residuals is time invariant or homoscedastic. For a regression model is considered as best fit when $\mu=0, \sigma=$ constant (Homoscedastic). The result of Breush Pegan test is significant @ 5\% showing the variance of residuals is homoscedastic. Therefore, it is inferred that VIX has the power to influence the market index.

\subsection{ARMA Model Forecasting}

Auto Regressive Moving average model is used to examine the predictive power of the lag variable in forecasting the dependent variable. The model consists of two parts, an autoregressive and moving average component. The autoregressive component considers the lagged values of the dependent variable and moving average is the linear combination of error terms. We 
Table 6. ARIM model forecasting of Nifty returns

\begin{tabular}{|l|l|l|l|l|}
\hline Variable & \multicolumn{4}{|c|}{ Dependent Variable: NIFTY } \\
\hline & Coefficient & Std. Error & t-Statis-tic & Prob. \\
\hline C & 0.004524 & 0.005052 & 0.895545 & 0.3736 \\
\hline VIX & -0.109450 & 0.024670 & -4.436497 & 0.0000 \\
\hline AR(1) & 0.001834 & 0.120409 & 0.015229 & 0.9879 \\
\hline R-squared & 0.219991 & Mean dependent var & 0.004914 \\
\hline Adjusted R-squared & 0.197705 & S.D. dependent var & 0.048093 \\
\hline S.E. of regression & 0.043077 & Akaike info criterion & -3.411407 \\
\hline Sum squared resid & 0.129897 & Schwarz criterion & -3.317279 \\
\hline Log likelihood & 127.5164 & Hannan-Quinn criter. & -3.373895 \\
\hline F-statistic & 9.871260 & Durbin-Watson stat & 1.969094 \\
\hline Prob(F-statistic) & 0.000167 & & \\
\hline Inverted AR Roots & .00 & & \\
\hline
\end{tabular}

apply the first order ARMA model to forecast market volatility using implied volatility. The results are tabulated in the following Table 6.

ARMA model (Figure 6) is applied to forecast the market volatility using implied volatility as the independent variable. The goodness of fit of the model is analysed through Log-Likelihood function and Akaike Information Criterion (AIC). When comparing various orders of ARMA models, the one with lower AIC value is considered to be better for forecasting.
It is found that the ARMA $(1,1)$ model has the least AIC error (-3.411407) and LLF (127.5164). Hence it is inferred that ARMA $(1,1)$ is the appropriate model to forecast market volatility.

\subsection{Granger Causality Test}

We apply the Granger Causality test to examine the relationship between market return and implied volatility. Understanding the causal relationship between the two would facilitate the investors to develop trading strategies. If the implied volatility is

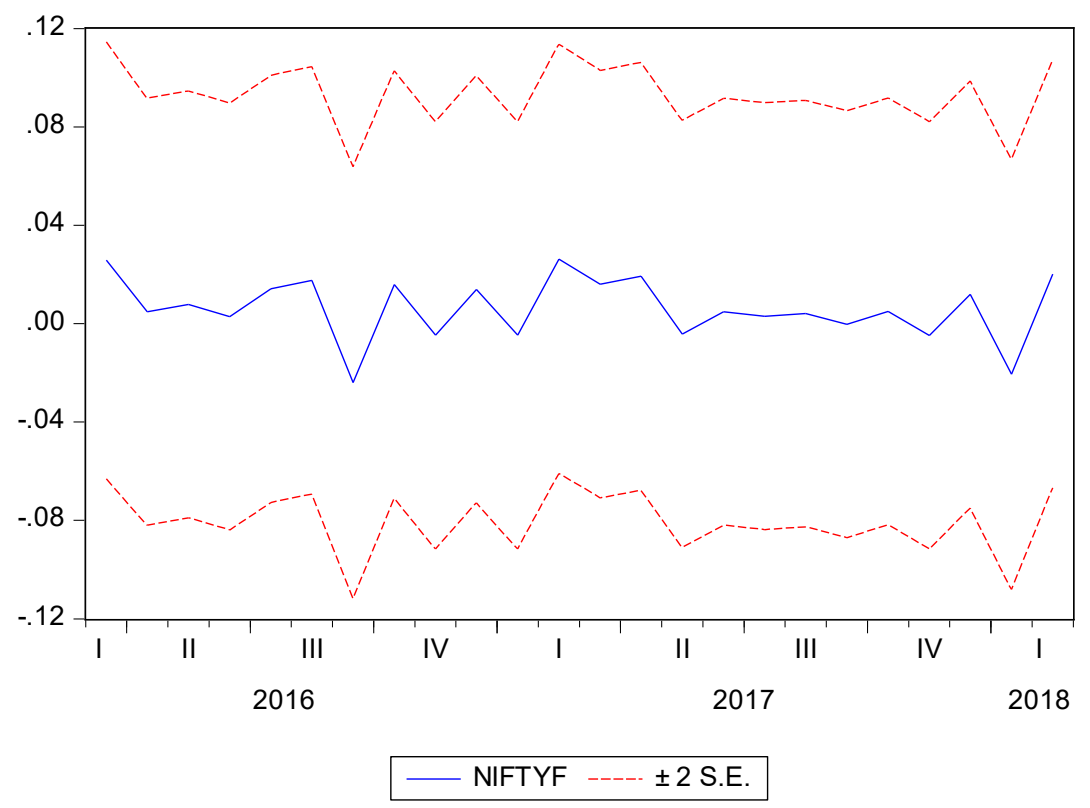

\section{Forecast: NIFTYF}

Actual: NIFTY

Forecast sample: 2016M03 2018M02

Included observations: 24

Root Mean Squared Error

Mean Absolute Error

Mean Abs. Percent Error

Theil Inequality Coefficient

Bias Proportion

Variance Proportion

Covariance Proportion
0.035516

0.027800

125.1068

0.679432

0.090863

0.373419

0.535718

Figure 5. ARMA model forecast of market volatility 


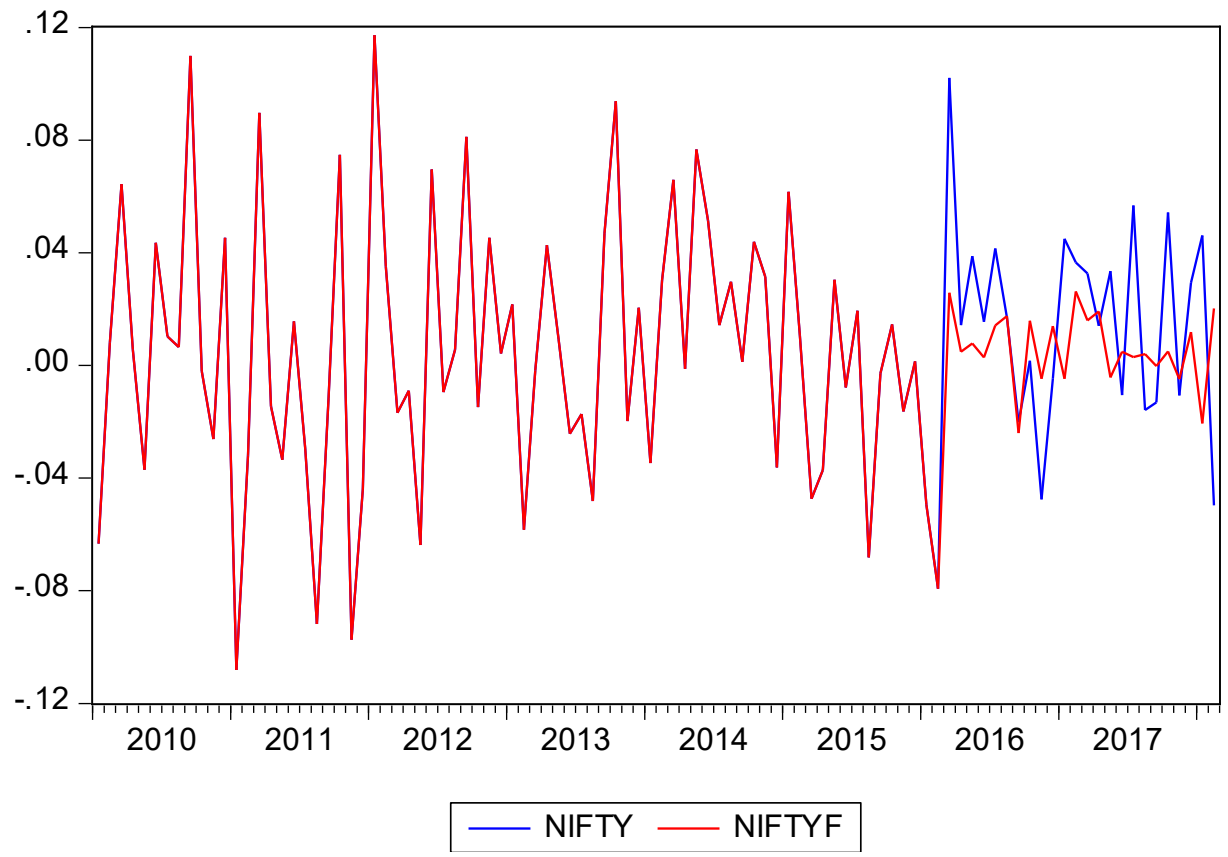

Figure 6. ARMA model.

said to Granger cause market return, then the patterns of volatility are expected to have an impact on the market return with a lag. It can be inferred that volatility has the predictive power to estimate returns and volatility. Table 7 shows the results of Granger Causality.

Table 7. Pair-wise Engle Granger Causality

\begin{tabular}{|l|l|l|l|}
\hline Pairwise Granger Causality Tests Lags: $\mathbf{2}$ \\
\hline Null Hypothesis & Obs & F-Statistic & Prob. \\
\hline VIX does not Granger Cause NIFTY & 2124 & 0.25951 & 0.7715 \\
\hline $\begin{array}{l}\text { NIFTY does not Granger } \\
\text { Cause VIX }\end{array}$ & & 9.18482 & 0.0001 \\
\hline
\end{tabular}

The output of the test indicates whetherimplied volatility is useful in forecasting volatility. The hypotheses are tested for both unidirectional and bidirectional causality. The significance of the results is examined using F Test. The results of Granger Causality test indicate unidirectional causality between NIFTY and VIX. However, there is no causality running from VIX to Nifty.

\section{Conclusion}

The two major types of volatility used in security analysis are historical and implied volatility. Historical volatility refers to the standard deviation of past returns. Modelling volatility requires an accurate estimate of future volatility. Experts and researchers have explored various models to forecast volatility. These models provide either static of dynamic forecast of future volatility. The forecasting models may be either univariate or bivariate. In the univariatemodel, the lagged values of the same variable are used to forecast the future value. The bivariate model includes an additional independent variable as a regressor in the equation. Using a bivariate model to forecast volatility necessitate the need to understand the dynamic relationship between two variables. The present study explores the predictive power of implied volatility to forecast market returns and future volatility. Application of forecasting model in the study shows implied volatility acts an appropriate indicator to forecast future volatility. Further, there exists a unidirectional causality between market return and implied volatility.

\section{References}

Abhijeet Chandra and Thenmozhi M. (2015). On asymmetric relationship of India volatility index (India VIX) with stock market return and risk management, DECISION (Springer India). 42(1). https://www.researchgate.net/ publication/273328438_On_Asymmetric_Relationship_ 
of_India_Volatility_Index_India_VIX_with_Stock_ Market_Return_and_Risk_Management

Costas Siriopoulos and Athanasios Fassas (2009). Implied Volatility Indices - A Review, SSRN Electronic Journal. https://www.researchgate.net/publication/228231105 Implied_Volatility_Indices_-_A_Review.

Christensen B.J. and Prabhala NR. (1998). The relation between implied and realized volatility, Journal of Financial Economics. 50(2):125-150. https://pdfs. semanticscholar.org/8180/6e9d63ecfa76fef96fe735e90d 20edc29fb8.pdf.

Emmanuel Anoruo and Vasudeva NR Murthy (2016). An examination of the REIT return-implied volatility relation: A frequency domain approach, Journal of Economics and Finance, Springer; Academy of Economics and Finance. 41(3): 581-94. https://ideas.repec.org/a/spr/jecfin/ v43y2019i1d10.1007_s12197-018-9442-1.html.

Henry Huang, Kent Wang and Zhanglong Wang (2016). A test of efficiency for the S\&P 500 index option market using the generalized spectrum method, Journal of Banking and Finance. 64(C):52-70. http://www.sciencedirect.com/ science/article/pii/S0378426615003167.

Imlak Shaikh and Puja Padhi (2014a). Inter-temporal relationship between India VIX and Nifty equity index,
DECISION (Springer India). 41(4). https://www. researchgate.net/publication/268882433_Inter-temporal_ relationship_between_India_VIX_and_Nifty_equity_ index

Imlak Shaikh and Puja Padhi (2016). On the relationship between implied volatility index and equity index returns, Journal of Economic Studies. 43(1):27-47. https://doi. org/10.1108/JES-12-2013-0198.

Karam Pal Narwal and Purva Chhabra (2018). An insight of implied volatility Vis-a-Vis its informational efficiency, association with underlying assets and spillovers effects, Asian Journal of Management. 9(2). http://ajmjournal. com/AbstractView.aspx?PID=2018-9-2-17.

Kumar, S. (2012). A first look at the properties of India's volatilityindex, International JournalofEmerging Markets. 7(2). https://doi.org/10.1108/17468801211209938.

Percheklii, D. (2014). Comparison between implied and historical volatility forecasts: Evidence from the Russian stock market. A thesis submitted in partial fulfillment of the requirements for the degree of MA in Economic Analysis, Kyiv School of Economics; 34p. http://www. kse.org.ua/download.php?downloadid=393. 